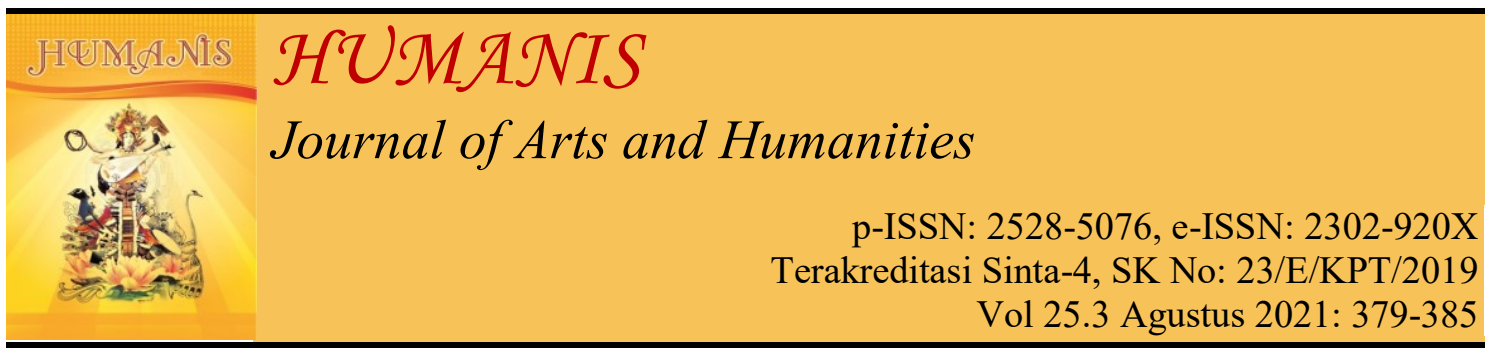

\title{
Tinder Sebagai Platform Pencarian Jodoh di Zaman Digital
}

\author{
Cinthya Fatama Prima, I Nyoman Suarsana, Ni Made Wiasti
}

Universitas Udayana, Denpasar, Bali, Indonesia.

Email korespondensi: cinthyafprima@gmail.com, inyomansuarsana.58@,gmail.com, mwiasti@yahoo.com

\begin{tabular}{|c|c|}
\hline Info Artikel & Abstract \\
\hline $\begin{array}{l}\text { Masuk:25 April } 2021 \\
\text { Revisi: } 2 \text { Juni } 2021 \\
\text { Diterima: } 10 \text { Juni } 2021 \\
\text { Keywords: Love, Dating App, } \\
\text { Digital Era, Phenomenon, } \\
\text { Match, Tinder }\end{array}$ & $\begin{array}{l}\text { The phenomenon of dating applications is increasingly growing } \\
\text { in society. This is evidenced by the rise of dating applications. } \\
\text { Tinder is one of the most talked about dating apps. Tinder } \\
\text { brings people a change in the way it is social. Since Tinder was } \\
\text { launched, now humans can easily make new friends virtually. } \\
\text { Dating applications are believed to be able to provide a } \\
\text { solution when a match comes for its users. This is what attracts } \\
\text { researchers to dig deeper into the phenomenon of matchmaking } \\
\text { through the Tinder application as a matchmaking platform in } \\
\text { the digital era. The theory used by the researcher is social } \\
\text { action theory and theory of love by Wheel theory. This research } \\
\text { also uses a qualitative descriptive method and a qualitative } \\
\text { approach. The results show that the resource person uses the } \\
\text { Tinder application to find new friends, girlfriends and even } \\
\text { husbands / wives. The researcher concluded that the actions } \\
\text { taken by the informants on average had the same answer. This } \\
\text { action is done for the purpose of finding a new socials circle. }\end{array}$ \\
\hline & Abstrak \\
\hline $\begin{array}{l}\text { Corresponding Author: } \\
\text { Cinthya Fatama Prima,Email: } \\
\text { cinthyafprima@gmail.com } \\
\text { DOI: } \\
\text { https://doi.org/10.24843/JH.20 } \\
\text { 21.v25.i03.p15 }\end{array}$ & $\begin{array}{l}\text { Fenomena aplikasi kencan semakin marak berkembang di } \\
\text { masyarakat, Hal ini banyak dibuktikan dengan maraknya } \\
\text { aplikasi pencarian jodoh. Tinder adalah salah satu aplikasi } \\
\text { kencan yang sedang ramai diperbincangkan. Tinder } \\
\text { menyuguhkan perubahan kepada masyarakat dalam cara } \\
\text { bersosialisasi. Semenjak Tinder diluncurkan, kini manusia bisa } \\
\text { dengan mudah mendapatkan teman baru secara virtual. } \\
\text { Aplikasi kencan diyakini dapat memberikan solusi kapan } \\
\text { datangnya jodoh bagi penggunanya. Hal ini yang menarik } \\
\text { peneliti untuk menggali lebih dalam bagaimana fenomena } \\
\text { pencarian jodoh melalui aplikasi Tinder sebagai platform } \\
\text { pencarian jodoh di zaman digital. Teori yang digunakan } \\
\text { penelitiadalah teori tindakan sosial dan teori pencarian jodoh. } \\
\text { Penelitian ini juga menggunakan metode deskriptif kualitatif } \\
\text { dan pendekatan kualitatif. Hasil penelitian menunjukan bahwa } \\
\text { narasumber menggunakan aplikasi Tinder adalah untuk } \\
\text { mencari teman baru, pacar bahkan suami/istri. Peneliti } \\
\text { menyimpulkan bahwa tindakan yang dilakukan oleh informan } \\
\text { rata-rata memiliki jawaban yang sama. Tindakan ini dilakukan } \\
\text { untuk tujuan mencari circle sosial baru. }\end{array}$ \\
\hline
\end{tabular}




\section{PENDAHULUAN}

Teknologi sangat berkaitan dengan internet. Kemajuan teknologi saat ini membuat keberadaan internet semakin berkembang. Perkembangan yang terjadi terhadap handphone juga sangat mempermudah manusia untuk berkomunikasi dan bersosialisasi melalui media sosial. Hanya melalui sebuah handphone, manusia bisa dengan mudah mendapatkan begitu banyak informasi secara cepat. Dalam sebuah handphone terdapat pula aplikasi yang beraneka ragam.

Kemajuan teknologi sangat mempengaruhi cara manusia di seluruh dunia dalam mencari rekan atau pasangan hidup melalui media sosial. Dari sekian banyaknya media sosial, terdapat banyak situs biro jodoh yang bisa membuat penggunanya menemukan jodoh secara online. Menurut kamus besar Bahasa Indonesia, biro jodoh berarti sebuah jasa yang menjodohkan seorang pria atau wanita, biro jodoh juga sering diartikan sebagai layanan yang membantu seseorang untuk mendapatkan pasangan hidupnya. Seiring dengan majunya teknologi, kini hal tersebut bisa dilakukan via online .

Tinder diciptakan di tahun 2012 oleh Sean Rad, Jonathan Badeen, Justin Mateen yang merupakan sekumpulan mahasiswa dari University of Southern California, mereka merancang aplikasi Tinder guna memudahkan manusia yang ingin mendapatkan teman di luar jejaring sosialnya. Aplikasi Tinder kini sedang marak digunakan oleh banyak masyarakat muda. Yang membuat Tinder lebih diminati adalah penggunanya dapat berinteraksi satu sama lain saat keduanya telah "matches" atau saling menekan tombol hati. Disisi lain, Tinder juga dilengkapi dengan fitur galeri foto dan menunjukkan ketertarikan yang sama diantara penggunanya yang mungkin menjadi penentu untuk menyukai pengguna lainnya. (dilansir dari www.pressburner.com/apa-itu-Tinder/)

Tinder merupakan aplikasi gratis yang bisa didapatkan di smartphone. Sistem kerja aplikasi ini adalah dengan memanfaatkan sistem satelit navigasi yang dapat mengatur jarak dan lokasi. karena Tinder ingin memudahkan penggunanya untuk menggunakan aplikasi tersebut. Hanya dengan menyentuh dan menggeser layar ke kiri atau kanan pengguna dapat menolak atau memilih pengguna Tinder lainnya.

Berdasarkan hasil survei Rakuten Insight di Indonesia pada September 2020, Tinder adalah aplikasi daring paling banyak digunakan di Indonesia. Hal ini dibuktikan dengan meningkatnya jumlah swipe yang mencapai tiga miliar swipe pengguna dalam sehari pada 29 Maret 2020 atau saat awal pandemi Covid-19 sehingga Tinder berhasil mendapatkan rekor pengguna terbanyak. aplikasi Tinder ini turut menjadi aplikasi kencan online yang cukup familiar dengan generasi milenial, maka dari itu peneliti menganggap Tinder adalah wadah kencan online yang cukup diminati dalam penelitian yang peneliti teliti karena cukup dekat dengan kawasan sekitar peneliti. Seperti kisah yang terjadi kepada Adrian, salah satu narasumber peneliti yang menemukan kekasih hatinya melalui aplikasi kencan online Tinder. Awalnya Adrian hanya iseng bermain Tinder karena ia baru saja putus dengan mantan kekasihnya saat itu. Setelah beberapa kali match, Adrian menemukan satu wanita yang dirasa cocok dengan kriterianya. Setalah melakukan perkenalan dan berbincangbincang, Adrian sudah merasakan kenyamanan dan kecocokan dengan wanita tersebut dan merencanakan kencan pertamanya . melakukan pendekatan selama dua bulan, Adrian mulai menyatakan perasaan kepada wanita tersebut. Hingga saat ini, 
hubungan keduanya masih berjalan dan bertahan. Adrian sendiri tidak menyangka bahwa jodohnya datang dari Tinder. Menurutnya, Tinder tidak selalu tentang hal-hal yang buruk, tergantung bagaimana pengguna itu sendiri dalam menggunakan sosial media.

\section{METODE DAN TEORI}

\section{Metode}

Penelitian ini bersifat kepustakaan dengan objek aplikasi kencan online Tinder. peneliti menggunakan data kualitatif yang dilakukan berdasarkan pencatatan secara deskriptif atas hasil observasi, wawancara mendalam maupun wawancara bebas serta dokumendokumen tertulis lainnya dan juga melakukan komunikasi secara virtual melalui facebook, Instagram, whatsapp, dan lain-lain. Penelitian dilakukan untuk mendapatkan informasi tentang pengguna Tinder di Kota Malang. Analisis data didapatkan menggunakan teknik deskriptif kualitatif. Ada dua sumber data yang diperoleh dalam penelitian ini yaitu sumber data primer dan sumber data sekunder. Data primer didapat dengan melakukan observasi dan interview secara langsung kepada 3 informan yang memiliki rentang usia dari 23 tahun hingga 25 tahun yang berprofesi sebagai mahasiswa dan berlokasi di Kota Malang, Jawa Timur. Kemudian data sekunder diperoleh dari dokumen. Catatan serta berbagai refrensi seperti jurnal serta laporan. Teknik yang dilakukan peneliti saat penelitian adalah observasi, wawancara dan studi pustaka yang diperoleh dan dikumpulkan dengan menggunakan panca indra, teknik wawancara dengan menentukan informan pangkal dan informan kunci melalui teknik purposive sampling agar data yang diperoleh bisa representatif dan teknik studi pustaka yang didapat dari buku, maupun jurnal sebagai referensi tambahan.Peneliti menggunakan tahapan analisis data. Dalam data deskriptif kualitatif tersebut peneliti berusaha mendeskripsikan atau menjelaskan tentang Tinder sebagai platform pencarian jodoh di zaman digital.

\section{Teori}

Penelitian ini menggunakan teori pencarian jodoh dari Rheiss \& Wheel

Menurut Reiss - Wheel (dalam Olson \& Defrain, 2003 ) , Manusia mencari pasangan dengan berbagai tahapan sebagai pemenuhan kebutuhan untuk berinteraksi sosial. Tahapan pencarian pasangan pada teori Reiss dan Wheel memiliki pola tersendiri, antara lain:

1. Rasa ketertarikan yaitu perasaan yang rata-rata mengarah pada sesuatu yang nilainya alami karena objek mata adalah keindahan. Apabila terdapat sesuatu yang menarik didepan mata secara otomatis seseorang akan memusatkan perhatian.

2. Membuka diri yaitu seorang individu yang bisa membuka diri dengan memulai membuka obrolan dengan individu yang baru saja di kenal di media sosial tetapi belum pernah bertemu secara langsung. Biasanya percakapan ini dimulai dari hal-hal kecil.

3. Keterikatan yang sifatnya timbal balik yaitu perkenalan yang semakin intens dengan saling bertukar pengalaman dan hal-hal yang sering di lakukan yang membuat rasa keterikatan yang sifatnya menguntungkan satu sama lain. Kedua individu tersebut akhirnya menjadi saling bergantung satu sama lain.

4. Tumbuhnya cinta yakni dalam menentukan suatu kesamaan dalam diri calon pasangan termasuk rasa empati, rasa saling mengerti, menghormati, saling berkorban, saling menghargai, dan saling mendukung, dalam hal kebaikan. Rasa saling cinta 
ini bisa semakin tumbuh, dan memungkinkan mengarahkan keduanya pada keputusan untuk menikah.

Teori Reiss - Wheel ini dapat dibuktikan dengan adanya perilaku seluruh informan yang ada dalam penelitian ini yang memang melalui tahapan-tahapan sesuai dengan isi teori seperti memiliki rasa ketertarikan kepada pengguna Tinder lain kemudian masuk ke fase membuka diri seperti pendekatan sebelum akhirnya memutuskan untuk bertemu hingga akhirnya tumbuh cinta di antara kedua penggunanya.

\section{HASIL DAN PEMBAHASAN}

\section{Kisah Adrian}

"Main Tinder udah dari awal lulus SMA tapi pas itu posisi gue lagi di Bogor dan kebetulan abis break up juga sama mantan pas itu. Biasalah main aplikasi gituan buat cari pelampiasan aja sih kalo bocah baru putus kan, hahaha. Tau Tinder sih karena dulu emang lagi jaman jamannya Tinder kan, yaudah iseng download,main.. main.. main.. ada tuh yang match, ngobrol ngobrol, cocok, yaudah gaskeun ketemuan kebetulan satu kota yaudah gas. Pas ketemu, asik nih orangnya, cara dia ngobrol langsung sama Bahasa dia di chat agak beda gitu sih lebih dewasa pas ketemunya dan gue ngerasa sosok dia lebih asli aja lah pas ketemu, terus gue ajak jalan, nonton , ngobrol, pas udah sekitar 2 bulan deket kok sama sama nyaman gitu, kan, yaudah gue beraniin aja nembak dia pas itu dan diterima. cuma sekarang posisi kita lagi ldr-an , gue di Malang dianya di Yogyakarta sekarang dia S2, gue masih S1 sih, jadi ya terbantu aja dan makasih banget sama Tinder ini karna ganyangka aja jodoh gue datengnya dari Tinder, kan biasanya kebanyakan kalo orang awam gitu kan mandang Tinder kek aplikasi ga bener gitu kan, padahal kalo mereka tau dan beneran paham teknologi sih bakal ketemu juga kan benefit nya main Tinder apaan ga Cuma dari sisi negatifnya aja di liat, toh kita ketemu banyak banget orang nantinya di Tinder ini dengan berbagai macam background atau personality nya. Tinggal gimana kita nya aja yang nanggepin gitu kan" (Adrian, 2020)

Sadar bahwa ia sudah merasa cocok dengan wanita yang ia temui di Tinder, Adrian pun mulai merencanakan pertemuan dengan wanita tersebut. Dalam kurun waktu dua bulan, keduanya merasa cocok dan sama-sama merasa nyaman dan memutuskan untuk menjalin hubungan,namun kini keduanya menjalani hubungan jarak jauh. Menurut Adrian, dirinya merasa terbantu dengan adanya aplikasi Tinder sebab dari aplikasi ini ia dengan mudahnya menemukan cinta sejatinya tanpa harus bertemu terlebih dahulu untuk berkenalan. Adrian juga mengatakan bahwa Tinder tidak melulu tentang hal buruk. Jika seseorang benar paham cara menggunakan teknologi dengan baik, pasti akan mendapatkan keuntungan atau benefit dari aplikasi Tinder ini, tinggal bagaimana pengguna tersebut menerapkannya.

\section{Kisah Bilqisya}

Bilqisya merupakan salah satu Mahasiswa pengguna aplikasi Tinder berusia 22 tahun yang menempuh pendidikan di Universitas Negeri Malang. Awal Bilqisya mencoba Tinder adalah di tahun 2015 dari temannya saat ia berusia 17 tahun. Melalui Tinder ia dapat menemukan orang baru dengan karakteristik yang belum pernah ia temui sebelumnya. "Gua main Tinder udah dari kapan ya, kayanya udh lima taunan dah, tau Tinder juga dari temen karna dia juga pake aplikasi Tinder, kan. Tujuan gua main Tinder sebenernya ya nyari temen biasa aja si kalo cocok kan berarti bisa lanjut ke yang lebih serius. Selain Tinder, 
gua juga ada main beberapa dating apps lain kaya bumble, hook, OKCupid, sama tantan. Semuanya pake data diri asli,yaa biar gampang dikenali aja pas ketemu." (Bilqisya, 2020)

Latar belakang Bilqisya menggunakan tinder adalah untuk mencari pacar dan teman nongkrong. Bilqisya selalu bisa mendapatkan teman baru melalui Tinder karna Bilqisya termasuk anak yang mudah bergaul.

"aku cari temen buat nongkrong aja gitu karna kan aku emang suka ngopi kan, Aku juga udah sering banget main sama anak Tinder." (Bilqisya, 2020)

\section{Kisah Nabila}

Nabila merupakan salah satu Mahasiswa pengguna aplikasi Tinder berusia 23 tahun yang menempuh pendidikan di Universitas Negeri di Malang. Alasan Nabila menggunakan aplikasi Tinder adalah hanya untuk mengisi kekosongan di hari-harinya. Nabila sendiri sudah memiliki kekasih yang mana ia juga dapatkan dari Tinder. Namun, meskipun keduanya telah berpacaran, Nabila dan kekasih tetap menggunakan aplikasi Tinder di keseharian mereka. Tujuannya adalah hanya sekedar untuk menambah relasi pertemanan dan sosial.

"Paling main Tinder ya gabut doang, pacar aku tau aku main Tinder dan selama aku ga melenceng sih dia ga masalah kok. Di Tinder kan ga cuma nyari pacar doang, tau tau ketemu rekan bisnis kan untung juga, kalo jaman dulu kan orang mikir kalo kenalan di dating app gitu kesannya jelek gitu kan kenalan kok lewat sosmed tapi makin kesini malah orang orang dapet apa apa juga dari sosmed kan, banyak kok yang pacaran kenalan nya dari dating apps, ada banyak kasus yang sampe nikah juga kan" (Nabila, 2020)
Nabila mengaku bahwa menggunakan aplikasi Tinder ini tidak melulu hal yang buruk, menurutnya, banyak manfaat yang bisa didapatkan Nabila di dalam aplikasi Tinder ini. Tak jarang juga pengguna Tinder yang berhubungan sampai ke jenjang pernikahan

\section{Tinder Sebagai Platform Pencarian Jodoh di Zaman Digital.}

Teknologi yang maju dan berkembang sangat mendukung manusia di seluruh dunia dalam mencari teman atau pasangan hidup melalui media sosial. Dari berbagai macam media sosial yang ada, terdapat banyak situs biro jodoh yang bisa membuat penggunanya mendapatkan jodoh secara virtual. Menurut kamus besar Bahasa Indonesia, biro jodoh berarti sebuah jasa untuk menyatukan seorang pria dan wanita, dengan ibarat lain biro jodoh bisa disebut sebagai sebuah jasa berbayar yang membantu seseorang untuk mendapatkan pasangan. Seiring dengan berkembangnya teknologi, kini mencari jodoh bisa didapatkan secara online. Banyak pengguna media sosial yang meyakini bahwa media sosial adalah teknologi yang menjanjikan dalam mencari rekan atau pasangan yang dimana hanya dengan menggunakan handphone sudah mampu mengakses media sosial dimanapun dan kapanpun. Tingkat pergerakan yang tinggi pada masyarakat kota terutama bagi kalangan mahasiswa dengan banyaknya kegiatan dikampus dan tugas kuliah membuat mahasiswa mau tidak mau harus pandai mengatur waktu. Kurangnya interaksi sosial pada masyarakat perkotaan dikarenakan padatnya kesibukan, membuat mereka tidak mengutamakan menjalin hubungan percintaan, bagi kebanyakan penduduk kota, memiliki pasangan kerap menjadi nomor kesekian karena lebih mengutamakan pendidikan. 
Di Indonesia terdapat beragam aplikasi atau situs pencarian jodoh yang terdapat di dalam ponsel yang dapat di unduh sesuai keinginan, diantaranya ada aplikasi pencarian jodoh yang cukup terkenal di Indonesia banyak di gunakan di Indonesia seperti bumble, hinge, okcupid dan tinder. Penelitian ini dilakukan di kota Malang dengan fase kesibukan mahasiswa yang cukup padat membuat banyaknya masyarakat yang memilih cara cepat untuk mendapatkan pasangan hidup melalui platform pencarian jodoh yang mudah dan cepat diakses.

Dalam aplikasi Tinder juga terdapat jarak lokasi dari pengguna terhadap lokasi pengguna lainnya, sehingga untuk mencari pasangan dapat dilihat juga dimana pengguna tersebut tinggal. Adanya jarak lokasi ini tentu akan memudahkan pengguna yang memang ingin mencari pasangan dalam satu kota atau yang berjarak dekat. Dalam aplikasi Tinder proses pencarian diberikan dua opsi yaitu menggeser ke kanan dan menggeser ke kiri. Geser kanan berarti pengguna menyukai pengguna lainnya, sebaliknya dengan geser kiri berarti pengguna menunjukkan tidak tertarik dengan pengguna tersebut. Tak jarang juga ditemukan pengguna yang dinyatakan matches dengan pengguna lainnya. Setelah dirasa memiliki ketertarikan dengan pengguna lainnya, maka pengguna dapat melakukan chat pribadi untuk melakukan perkenalan yang nantinya dapat memberikan penilaian secara personality. Jika memang dirasa cocok dan nyaman maka pengguna akan melakukan proses pertemuan bahkan hingga pacaran dan menikah.

\section{SIMPULAN}

Penggunaan aplikasi Tinder di zaman digital ini mendorong terjadinya perubahan dalam proses pencarian jodoh. perubahan tersebut merupakan refleksi dari kehidupan kaum milenial zaman digital. Proses pencarian jodoh menjadi lebih privasi, cepat, dan mudah direalisasikan.

Dalam proses pencarian pasangan hidup pada pengguna yang paham teknologi cenderung cepat karena dipandang memiliki intelektual dan pengetahuan yang bagus serta tentunya memiliki sudut pandang yang berbeda terhadap suatu hubungan. Berbeda dengan seseorang yang tidak paham teknologi, mereka akan cenderung memandang Tinder sebagai suatu aplikasi yang buruk dan tidak berguna.

\section{DAFTAR PUSTAKA}

Ardianto, Elvinaro. (2007). Komunikasi Massa Suatu Pengantar. Bandung : Simbosa Rekatama Media

Bungin, Burhan. (2001). Metodologi Penelitian Sosial. Surabaya: Universitas Airlangga

Bungin, Burhan . (2008). Sosiologi Komunikasi. Jakarta: Prenada Media Grup

Fridha, Merry dan Meria Octavianti. (2016).Mengenai konstruksi makna kencan di situs pencarian jodoh . Skripsi, Universitas Islam Balitar. Dan Universitas Padjadjaran.

George, R. (2001). Sosiologi Ilmu Berparadigma Ganda. Jakarta: PT Rajawali

Hidayat, Ahmad. (2015). Pengurangan Ketidakpastian dalam Komunikasi Lintasbudaya [Skripsi]. Yogyakarta: Universitas Negeri Sunan Kalijaga

Kamus Besar Bahasa Indonesia. (2013). Edisi ke-empat. Jakarta: 
Departemen Pendidikan dan Kebudayaan RI.

Mareta, Dwina. (2017). Fenomena pengguna aplikasi Tinder di kalangan mahasiswa di Kota Bandung. Skripsi, Universitas Pasundan Bandung.

Mulyana, Deddy \& Jalaludin Rakhmat. (2000). Komunikasi Antara Budaya:Panduan Berkomunikasi Dengan Orang-Orang Berbeda Budaya. Bandung : Remaja Rosdakarya

Mulyana, Deddy \& Jalaludin Rakhmat. (2004). Komunikasi Efektif. Bandung: Remaja Rosdakarya

Nasrullah, Dr. Rulli. (2015). Media Sosial (Cetakan Pertama). Bandung: Simbiosa Rekatama Media

Novala, Putri Tessa. (2015).Motif Pria Pengguna Tinder Sebagai Jejearing Sosial Pencarian Jodoh(Studi Virtual Etnografi Mengenai Motif Pria Pengguna Tinder). Skripsi, Universitas Telkom Bandung.

Nurfazila, Anggita. (2015). SelfDisclosure Perempuan Muda Di Platform Online Dating . [Skripsi]. Universitas Indonesia

Olson \& Defrain. (2003). Marriage \& Families $\left(4^{\text {th }} E d\right)$. New York: MC Graw Hill

Rakhmat, Jalaluddin. (2007). Psikologi Komunikasi. Bandung: PT Remaja Rosdakarya
Sari, Dewi Rosita. (2016).Perilaku komunikasi pengguna media sosial tinder dalam menjalin relasi pertemanan di kalangan mahasiswa UNIKOM (Studi Deskriptif Tentang Perilaku Komunikasi Pengguna Media Sosial Tinder Dalam Mennjalin Relasi Pertemanan di Kalangan Mahasiswa Unikom). Skripsi, Universitas Komputer Bandung

Severin, Werner J. dan James W. Tankard. (2005). Teori Komunikasi: Sejarah, Metode, dan Terapan di Dalam Media Massa. Jakarta: Kencana

Shafira.(2010).Take Me Out Indonesia Realitas Pencarian Jodoh Perempuan Melalui Media. Skripsi, Universiatas STAIN Sjech M. Djamil Djambek Bukit tinggi.

Singarimbun, Masri \& Sofyan Effendy. (1995). Metode Penelitian Survey. Jakarta: LP3ES

Sudarman, Momon. (2014). Sosiologi Komunikasi, Cetakan Pertama. Jakarta: Mitra Wacana Media

Sugiono. (2005). Memahami Penelitian Kualitatif.Bandung: Alfabeta

Usman, Husnaini \& Purnomo Setiady Akbar. 2008. Metodologi Penelitian Sosial. Jakarta: PT. Bumi Aksara 